\title{
Excess Weight, Obesity, Diabetes and Coronavirus Disease
}

\author{
Gundu H R Rao* \\ Emeritus Professor, Laboratory Medicine and Pathology Director, Thrombosis Research, Lillehei Heart Institute, University of Minnesota, \\ USA
}

*Corresponding author: Gundu H R Rao, Emeritus Professor, Laboratory Medicine and Pathology Director, Thrombosis Research, Lillehei Heart Institute, University of Minnesota, USA

\section{Introduction}

SARS-CoV-2 virus has created an unprecedented public health and global economic crisis. Despite the fact, that this virus was discovered half a century ago, earlier version of this RNA virus (SARS$\mathrm{CoV}$ ) was less virulent than the 2019 version of the virus (CoV-2), which turned out to be the most potent killer virus. According to the Johns Hopkins University (JHU) Coronavirus Resources Center (coronavirus.jhu.edu), globally there are 28 million Covid-19 infected individuals and 900,000 deaths. In the USA, we have over 6.4 million infected individuals and 192,000 confirmed covidrelated deaths. The response from the public health perspective is important, to prevent further escalation of the SARS-CoV-2 epidemic. Having said that, it is important to note, that each country has responded differently. Vietnam, and Taiwan have done well in keeping the Covid-19 infection rate and death to a minimum. Public health experts worldwide, should study the response of Taiwan, in preventing the spread of this highly contagious disease, without massive tests and lockdowns. Currently the oldest (USA) and the youngest (India) democracies, are competing for the number one position, interns of highest number of infected individuals. India has over 4.5 million infected individuals and 76,000 deaths. According to the JHU report dated September 10,2020, Mexico has the highest observed case-fatality ratio (CFR) of $10.7 \%$, compared to the USA $(3.0 \%)$, and India (1.7\%). In earlier articles we have discussed the role of comorbidities such as hypertension, excess weight, obesity, diabetes (Type-2) and vascular diseases, on the severity of Covid-19 infection [1-6]. However, if one looks at this situation from a historic perspective, in the last four decades cardiometabolic disease such as hypertension, excess weight, obesity, diabetes (Type-2), and vascular diseases, have increased in prevalence and incidence to epidemic proportions worldwide [7-16]. Added to this global burden of metabolic diseases, a killer virus has taken advantage of the existence of these metabolic risks, which are known to promote, oxidative stress, inflammation, vascular and immune dysfunction.
China Medical Treatment Expert Group for Covid-19, reported in January of 2019, that on admission, $20-51 \%$ of patients reported as having at least one comorbidity, with diabetes (10-20\%), hypertension (10-15\%), and other cardiovascular diseases (7$40 \%$ ) being the most common [17]. In this guest editorial, we will briefly discuss the role of metabolic diseases such as hypertension, obesity, and diabetes in the progression and severity of the coronavirus disease. According to news reports, the first group of people to get hit by the virus in Italy were the elderly. They also noted that Italy has the second oldest population in the world, after Japan. Irony of this comparison is, that Japan did not suffer such devastating effect from the SARS-CoV-2 as Italy and Spain. In China, of the 1590 patients hospitalized in the early days of Covid-19 pandemic, the mean age was 48.9 years. In the USA, rates were highest among persons aged 65 years (12.2\%), 65-74 (17.2\%), and population older than 85 (54.4\%). Public health experts believed that younger population was less susceptible for the SARS-CoV-2 infection. As is with any prediction about the Covid-19, the story keeps changing as the timeline changes. Currently there are over 500,000 infected young students in the USA. Earlier reports from China, indicated hypertension and diabetes (Type-2) as the two major comorbidities. However, in the recent months, dozens of studies have reported that many of the sickest patients have been people with obesity [18]. Furthermore, studies have demonstrated that even people who are merely overweight, also are at higher risk for Covid-19. The study by Ogden et al reported, the prevalence of childhood and adolescent obesity, and noticed grater increases (2-fold) in non-Hispanic Black and Mexican American adolescents [19]. This is particularly concerning, because adolescents with severe obesity are at high risk for the development of serious comorbidities including hypertension, diabetes as well as Covid-19. In a recent editorial in JAMA, Rodgers and Gibbons discuss the role of obesity and hypertension as comorbidities of Covid-19. SARSCoV-2 pandemic has brought out the susceptibility of minority 
communities of color, and has exposed the complex interplay of contributing factors, that are rooted in the social determinants of health, and racial inequities. A 6-fold increase in the rate of death for African Americans, living in the USA due to a ubiquitous virus should be deemed unconscionable, as reported in the recent issue of JAMA (April15, 2020). What is currently known about these differences in disease risk and fatality rates? In Chicago, more than $50 \%$ of COVID-19 cases and nearly $70 \%$ of COVID-19 deaths involve African American individuals, although they make up only $30 \%$ of the population. This trend can me tracked down in various US Cities. Poor living conditions, health care disparity, unhealthy nutrition, and high incidence of metabolic diseases, seem to contribute to the excess CFR in this ethnic group, as well as in other minority communities $[20,21]$.

Considering the contribution of comorbidities to the progression and severity of the coronavirus disease, one would expect that China and India, with the largest populations of diabetic subjects, should have the highest CFR (Deaths per 100,000 population) for Covid-19. On the other hand, Mexico (10.7\%), Iran (5.8\%), and Spain (5.4\%) have lot more mortality than the USA (3.0\%) and India (1.7\%). Since the two major populations with highest number of diabetics have not shown comparatively high case fatality rate, it is worthwhile discussing the other two comorbidities (hypertension and obesity) as the chief contributors for the Covid-19 progression and severity. Trends in the prevalence of hypertension in the USA, according to the NHANCE survey of age standardized prevalence, decreased from $48.4 \%$ in $1999-2000$ to $45.4 \%$ in 2015-2016. However, absolute burden of hypertension consistently increased, from 87.0 million in 1999-2000 to 108 million in 2015-2016 [22]. Hypertension appears to be more common in Mexico, than among Mexican Immigrants in the United States. As far as the obesity goes, the number of obese children and adolescents aged five to 19 years, has risen tenfold in the past four decades and if current trends continue, there will be more obese children and adolescents than those moderately or severely [23]. Among adolescents, obesity prevalence in the USA was $16.8 \%$ in 2007 and $18.5 \%$ in 2016. Age standardized obesity in adults increased from $33.7 \%$ in 2007 to $39.6 \%$ in 2015 . Whereas, $62 \%$ of the participants in Mexico reported, at least, being overweight [24]. When considering obesity data based on the BMI, we should keep in mind that South Asians have a different body fat distribution, compared to the European and Western population. South Asians in general have central abdominal obesity.

Data from 6916 patient records that researchers from Kaiser Permanente reported, compared to normal body mass index (BMI) of $18-24 \mathrm{Kg} / \mathrm{m}^{2}$, the risk of death more than doubled for patients with a BMI of $40-44 \mathrm{Kg} / \mathrm{m}^{2}$ and nearly doubled again, for those with a BMI of $45 \mathrm{~kg} / \mathrm{m}^{2}$ or more [25] In an accompanying editorial, David A Kass, a Cardiologist at the Johns Hopkins University, wrote, "that these findings taken with prior research, -should put to rest the contention that obesity is common in severe COVID-19, -because it is common in the population." The pathophysiology of hypertension involves, complex interaction of multiple vascular effectors, including activation of the sympathetic nervous system, of the renin-angiotensin-aldosterone system, and of the inflammatory mediators. Oxidative stress and endothelial dysfunction are consistently observed in hypertensive subjects [26]. As we have discussed earlier, obesity has reached epidemic proportions worldwide. In the USA alone, the prevalence of obesity has increased $50 \%$ in the past three decades, with $70 \%$ of all adults being classified as either overweight or obese [27]. Beyond an impaired response to infections, people with obesity also suffer from chronic, low grade inflammation. Fat cells secrete inflammation triggering chemical messengers called cytokines, and more come from immune cells called macrophages, that clean up dead and dying fat cells. These in turn, impair vascular homeostasis and lead to endothelial dysfunction [28].

If we carefully analyze a series of clinical events, that develop post SARS-CoV-2 infection, we can begin to understand, why metabolic diseases serve as independent risk factors for the progression and severity of coronavirus disease. Initial route of entry is via nasal and oral mucosa, -the preferred receptor that facilitates the transmission seems to be the ubiquitous ACE2, which is found in multiple types of cells and tissue including vascular endothelium. Recent findings, that following the injury to the lung tissue, the virus gets entry into the endothelium, opens a whole new avenue for the progress of the disease and its severity. Endothelium is the largest organ of the body, covering a large surface area and reaching out to every tissue and organ. As such, the injury to the endothelium could introduce a cascade of events, leading to platelet activation, thrombin generation, and promotion of both thrombotic and thrombolytic events [3]. Furthermore, people with metabolic diseases such as, hypertension, excess weight, obesity, diabetes (Type-2), and vascular disease, already have a compromised endothelium and invasion of the SARS-CoV-2 virus leads to further injury to the vascular system, by the disruption of vascular integrity and endothelial cell death. These events lead to the exposure of the subendothelial basement membrane, and results in the activation of thrombotic and clotting cascade of events.

The question of why China and India with the largest populations of diabetics, have relatively low rates of Covid-related mortality, is quite puzzling. In China, -Covid-19 pandemic's epicenter, Wuhan, and its province, Hubei, Chinese Center for Disease Control-network, formed 1300 epidemic investigation teams, in addition to the 40,000 doctors and nurses. They used very clever tracing tools with big data support. In the first week of January the novel coronavirus infection was detected, and on 23 January 2020, they locked down the city of 11 million people and soon the rest of the Hubei-a province of nearly 60 million. The WHO-China Joint Mission on Coronavirus Disease 2019 Task 
Force concluded, "In the face of unknown virus, China has rolled out perhaps the most ambitious, agile, and aggressive, disease containment effort in history." The strategy that underpinned this containment effort was initially a national approach, that promoted universal temperature monitoring, masking, and hand washing [29]. As far as India is concerned, the general population thinks, that they have innate immunity, as they are exposed to a variety of Asian viruses. On the other hand, some scientists speculate that the SARS-CoV-2 in India is a milder version, compared to the European and US strains. According to a news report by Rajesh Nair in 'The Hindu' of September 11, 2020, "Diabetes seems to be the main cause of COVID-19 deaths in the Union Territories (UT) of India. A survey conducted by the Jawaharlal Institute of Postgraduate Medical Sciences and Research (JIPMER) showed 30\% of the government servants in Puducherry (UT) were diabetic.

In the same report by Nair, Emergency Surgeon of New Medical Center, Dr T. Arjun Sundaram expresses his optimism by saying, "It is an obedient (SARS-CoV-2) virus, if treated early for even people with comorbidities. But people with comorbidities try to ignore early symptoms, as part of their existing medical conditions, - just as flu-like symptoms." Comorbidities such as hypertension, excess weight, obesity, diabetes, and vascular diseases increase COVID-19 related hospitalization by 6 -fold and deaths, by 12 -fold. In a recent report from the USA, underlying conditions were reported in $71 \%$ of individuals admitted to hospital with COVID-19 and in 94\% of the deaths [30]. In a study done at Westchester County, New York, among Covid-19 patients, who presented with a comorbid condition, more than $57 \%$ had high blood pressure, while $41.7 \%$ were obese and $33.8 \%$ had diabetes. This study also found $90 \%$ of coronavirus patients, who were put on ventilators died. A recent global estimate published in Lancet, estimated that one in five individuals worldwide are at risk for infection by SARS-CoV-2 virus. A recent report by Jain and associates from New Delhi, India, discusses differential mortality in COVID-19 patients from India and Western Countries [31]. The authors discuss the age of the population, genetics of the virus, mutation of the virus, immune variations of Indian subjects and the expression of the ACE2 receptor in the adipose tissue.

Authors claim that they have investigated and identified the possible reasons and hypotheses for this disparity in observed or reported Covid-19 related mortality. However, we feel strongly, that there may be other, as yet unknown causes, and only future history will reveal all the mysteries of coronavirus disease.

\section{References}

1. Rao GHR (2020) COVID-19 and Cardiometabolic Diseases. EC Cardiol $7(6): 08-12$.

2. Rao GHR (2020) Coronavirus Disease and Acute Vascular Events. J Clin Applied Thrombosis Hemostasis 26: 1-4.
3. Rao GHR (2020) Coronavirus Disease (Covid-19): A Disease of the Vascular Endothelium. Series Cardiology Res 2(1): 23-27.

4. Rao GHR (2020) Coronavirus (COVID-19), Comorbidities, and Acute Vascular Events. EC Clinical Case Reports 3(6): 87-91.

5. Rao GHR (2020) Coronavirus Disease (Covid-19), Comorbidities, and Clinical Manifestations. EC Diab Met Res 4(6): 27-33

6. Rao GHR (2020) Covid-19: Anxiety, Stress, Fear and Heart Health. EC Cardiology 7(9): 14-17.

7. Rao GHR (2018) Cardiometabolic Disease: A global perspective. J of Cardiol Cardiovasc Ther 12(2): 1-6.

8. Rao GHR (2018) Excess weight, Obesity, Diabetes (Type 2) and Clinical Complications. Arch Diab \& Obesity Pp: 1-2.

9. Rao GHR (2018) Management of Diabetes Epidemic: Global perspective. EC Endocrinol Metab Res 3(2): 63-72.

10. Rao GHR (2018) Management of Excess weight and Obesity: A global Perspective. Interven in Obes, \& Diab 1(5): 108-112.

11. Rao GHR (2018) Obesity Epidemic: A global perspective. Interven in Obes \& Diab 2(1): 121-123.

12. Rao GHR (2019) Global Epidemic of Diabetes; Challenges and Opportunities. Ann Diab \& Endocrinol Research 1 (1): RD-DIA-10001.

13. Rao GHR (2018) Global Obesity and Diabetes epidemic: Where did we do wrong? Interven in Obes \& Diab 2(2): 154-155.

14. Rao GHR (2019) Global Syndemic of Metabolic Disease: Editorial Comments. J Diab and Clin res 1(1): 2-4.

15. Rao GHR (2019) Twin epidemics of Obesity and Diabetes: Call for Action. EC Endocrinol Metab Res 4 (6): 230-232.

16. Rao GHR (2019) The Tsunami of Cardiometabolic Diseases: An overview. J Daib Obe Meta Synd 1 (1): 1-9.

17. Guan W, Liang W, Zhao, Heng-rui Liang, Zi-sheng Chen, et al. (2020) Comorbidity and its impact on 1590 patients with Covid-19 in China: A Nationwide Analysis. Eur Resp J: 1-14.

18. Wadman M (2020) Why COVID-19 is more deadly in people with obesity-even if they're young. AAAS, USA.

19. Ogden CL, Fryar CD, Martin CB, Cheryl D Fryar, Deanna Kruszon-Moran, et al. (2020) Trends in obesity prevalence by race and Hispanic origin 1199-2000 to 2017-2018. JAMA 315(21): 2292-2299.

20. Rodgers GP, Gibbons GH (2020) Obesity and Hypertension in the Time of COVID-19. JAMA 324(12): 1163-1165.

21. Belanger MJ, Hill MA, Angelidi AM, Maria Dalamaga, James R. Sowers, et al. (2020) Covid-19 and Disparities in Nutrition and Obesity. N Engl J Med 383: e69.

22. Kirsten S Dorans, Katherine T Mills, Yang Liu, Jiang He (2018) Trends in Prevalence and Control of Hypertension According to the 2017 American college of Cardiology/American Heart Association (ACC/ AHA) Guideline. J Amer Heart Assoc 7(11).

23. NCD Risk Factor Collaboration (NCD-RisC) (2017) Worldwide trends in body-mass index, underweight, overweight and obesity from 19752016: a pooled analysis of 2416 population-based measurement studies in 128.9 million children, adolescents and adults. Lancet 390 (10113): 2627-2642.

24. Marco D DiBonaventura, Henrik Meincke , Agathe Le Lay, Janine Fournier , Erik Bakker, et al. (2018) Obesity in Mexico: Prevalence, Comorbidities, associations with patient outcomes, and treatment experiences. Diab Metab Syndr Obes 11: 1-10. 
25. Tartof SY, Qian Lei, Hong V, Rong Wei, Ron F Nadjafi, et al. (2020) Obesity and Mortality among patients diagnosed with Covid-19: Results from an Integrated Health Care Organization. Ann Intern Med M20-3742.

26. Schulz E, Gori T, Munzel T (2011) Oxidative stress and endothelial dysfunction in hypertension. Hypertension res 34(6): 665-673.

27. Katherine M Flegal, Margaret D Carroll, Cynthia L Ogden, Lester R Curtin (2010) Prevalence and trends in obesity among US adults, 1999-2008. JAMA 303(3): 235-241.

28. M Iantorno, U Campia, N Di Daniele, S Nistico, G B Forleo, et al. (2014) Obesity, Inflammation and endothelial dysfunction. J Biol Regulators \& Hemostatic Agents 28 (2): 169-176.

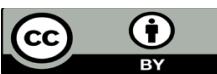

This work is licensed under Creative Commons Attribution 4.0 License

To Submit Your Article Click Here:

DOI: $10.32474 / A D 0.2020 .03 .000152$

29. World Health Organization (WHO) (2020) Report of the WHO-China Joint Mission on Coronavirus Disease 2019 (COVID-19). Pp: 1-40.

30. Andrew Clark, Mark Jit, Charlotte Warren-Gash, Bruce Guthrie, Harry H X Wang, et al. (2020) Global, regional and national estimates of the population at increased risk of severe COVID-19 due to underlying health conditions in 2020: a modelling study. Lancet 8 (8): e1003-e1017.

31. Vijay Kumar Jain, Karthikeyan Iyengar, Abhishek Vaish, Raju Vaishya (2020) Differential mortality in COVID-19 patients from India and western countries. Diab. Metab Syndr 14(5): 1037-1041.

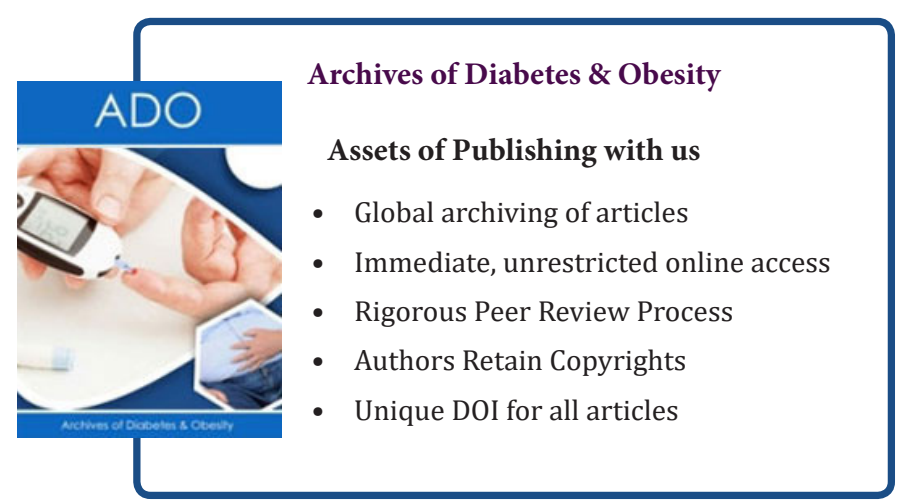

